\title{
A fronteira agrícola em Goiás: aspectos socioambientais
}

\section{The agricultural frontier in Goiás: socio-environmental aspects}

\author{
Denise Oliveira Dias ${ }^{1}$ \\ Hamilton Afonso de Oliveira ${ }^{2}$
}

\section{Resumo}

Trata-se de um artigo elaborado a partir do método histórico, cujo objetivo principal é descrever as mudanças provocadas pelo processo de implementação da produção capitalista no campo em Goiás. A princípio é apresentado o conceito de propriedade como processo histórico, em seguida se dispõe acerca da expansão da produção capitalista no campo, abordando a fronteira agrícola e o modo como ocorreu e ocorre a valoração da terra em decorrência desse fator de alteração dos meios de produção. Nos resultados do trabalho são apresentadas algumas consequências desse processo de expansão da produção capitalista, tanto sociais quanto ambientais.

Palavras-chave: História ambiental. Cerrado. Fronteira agrícola. História de Goiás.

\begin{abstract}
It is an article elaborated through the historical method, whose main objective is to describe the changes brought about by the process of implementing capitalist production in the countryside in Goiás. Initially, the concept of property as a historical process is presented. Then, the capitalist production expansion in the rural country is discussed, addressing the agricultural frontier and how the land valuation has occurred as a result of this factor of the means of production alteration. In the results section, some consequences of this process of expansion of capitalist production are presented, both social and environmental.
\end{abstract}

Keywords: Environmental history. Cerrado. Agricultural frontier. History of Goias.

\section{Introdução}

Trata-se de uma revisão bibliográfica sobre a ocupação do estado de Goiás, a partir do processo de expansão da fronteira agrícola. $\mathrm{O}$ trabalho está dividido em 3 tópicos principais, nos quais se discutem: a metodologia que foi utilizada para confeccionar o trabalho; a propriedade privada como um processo histórico em Goiás: como se desenvolveu a fronteira agrícola no território; e, por fim, sobre as consequências dessa expansão produtiva para o Cerrado em Goiás.

O método histórico estabelece que a realidade social pode ser entendida como um processo de construção histórica. Dessa maneira, neste trabalho de revisão para entender como a expansão da

\footnotetext{
${ }^{1}$ Doutoranda em Ciências Ambientais pela Universidade Federal de Goiás. Mestra em Ambiente e Sociedade pela Universidade Estadual de Goiás. Bolsista CAPES. E-mail: denisedias92@gmail.com

${ }^{2}$ Professor da Universidade Estadual de Goiás/ Campus Morrinhos-GO, no cursso de História e no Programa de Mestrado Ambiente e Sociedade (PPGAS). E-mail: hamiltonafonso@uol.com.br
} 
fronteira agrícola modificou as estruturas socioambientais do estado de Goiás, foi realizada antes da discussão principal um estudo sobre como foi implementada a propriedade privada no estado de Goiás. Demonstra-se que a edição da Lei de Terras de 1850 foi o marco processual de modificação do tratamento da terra como mercadoria, mas não pode ser a única responsável por essa transformação, pois a implementação de padrões produtivos tecnológicos foi fundamental para essa alteração na forma de lidar com a terra, sendo a lei um importante instrumento de transformação das relações sociais, contudo, não o único.

Esse processo de expansão da produção capitalista sobre o território goiano é descrito e dividido em alguns tópicos, sendo abordada a maneira como se desenvolveu esse processo e quem foram os agentes indutores e modernizantes, com o auxílio de pesquisadores que apresentam modelos descritivos como Martins (1975) e Miziara (2000). A expansão da produção capitalista no campo foi aprofundada pela existência da fronteira agrícola, que por sua vez foi possibilitada pela implementação do uso de tecnologia, incentivos governamentais e vontade individual dos agentes. Tal fator acabou por afetar diretamente a valoração da terra no território. Esse processo de ocupação e transformação do território em favorecimento das novas formas de produção no campo geraram consequências para o cerrado, por isso o último tópico do trabalho ocupa-se em descrever alguns desses impactos socioambientais sofridos pela penetração do modelo de produção capitalista no campo.

\section{Metodologia}

Para o desenvolvimento de um trabalho que visa tratar de temas que interseccionam áreas diversas da ciência, que são segmentadas em categorias diferentes e fragmentadas conforme o modelo metodológico tradicional cartesiano, faz-se essencial a utilização do método interdisciplinar como ferramenta, pois ele permite esse diálogo entre as disciplinas acerca de um tema comum. (JAPIASSU, 1994)

Utiliza-se como instrumento de pesquisa o método histórico, pois entende-se que o contexto histórico deve ser verificado como pressuposto do presente de determinada comunidade ou situação. Essa ideia advém de Marx (1818-1883), que por sua vez baseou-se na dialética hegeliana para formulá-la (ARANHA; MARTINS, 2009). Hegel (1770-1831) trouxe a ideia de que a história é uma espécie de processo social, por isso, para se estabelecer a verdade do presente, é necessário fazer uma varredura histórica dos acontecimentos passados. Nas palavras de Aranha e Martins (2009, p. 185): “o presente é engendrado por longo e dramático processo; a história não é simplesmente acumulação 
e justaposição de fatos acontecidos no tempo. Resulta de um processo cujo motor interno é a contradição dialética".

Marx (1818-1883) se afasta do pensamento hegeliano ao conceber que o processo histórico não se trata de uma jornada de desenvolvimento espiritual, mas de mudança histórica material. Enquanto Hegel (1770-1831) concebe o processo no plano das ideias espirituais, Marx (1818-1883) trabalha com o pensamento de que o fim do processo não seria um momento ideal de perfeição espiritual, mas um propósito maior e mais amplo de justa distribuição material, ou melhor, de igualdade, que seria atingido através da luta de classes (BUCKINHAM et al., 2011). Ou seja, a diferença central entre a dialética hegeliana da marxiana está na oposição entre idealismo e materialismo.

Dessa forma, este trabalho constitui uma reflexão teórica que reúne de forma interdisciplinar fragmentos que auxiliam na elucidação do tema central, que é a compreensão da maneira que se desenvolveu a valoração da terra no estado de Goiás e suas consequências socioambientais. Trata-se de uma revisão bibliográfica que tem o propósito de auxiliar na formação de conhecimento de História Ambiental do estado de Goiás por intermédio do método histórico que, apesar de basear-se no materialismo dialético, compreende suas limitações.

A metodologia utilizada para a compreensão dos fenômenos sociais analisados é baseada especialmente no olhar de Martins (2018), que entende a realidade como "processo social", passando a ideia de movimento e continuidade. O estudo socioambiental consegue estabelecer pontes interdisciplinares onde o ser humano não pode se desvincular do ambiente, o que enriquece o discurso histórico, ainda mais quando referente à uma determinada localidade, pois promove maior vínculo histórico e fortalecimento da memória do sujeito, gerando autonomia e emancipação.

Portanto, busca-se nesta pesquisa a compreensão dos fatos sociais promotores da expansão da Fronteira Agrícola sob o território do estado de Goiás, pois parafraseando Hobsbawm (1995), a tarefa de quem se dedica contar a história é essencialmente a compreensão, não o julgamento, e essa compreensão é refém da experiência histórica, por isso o método empregado para a realização é essencialmente a pesquisa histórica, que não se limita tão somente aos historiadores, mas se estende aos demais cientistas que se empenham na compreensão da realidade histórica em seus múltiplos aspectos.

\section{Propriedade fundiária como processo histórico}

A transição para a propriedade privada: visão geral 
A Lei de Terras (1850) foi promulgada no Brasil no século XIX. Ela dispunha sobre a condição da terra como mercadoria, ou seja, passível de apropriação mediante contrato de compra e venda. No entanto, em Goiás, a forma de lidar com a terra no sentido da apropriação do bem não foi alterada no século XIX, mas somente no início do século XX, mediante o processo de expansão capitalista de produção no campo, o qual pode ser entendido dentro da Frente Pioneira, que tem como um dos seus principais marcos a construção da Estrada de Ferro Goyaz. A partir dessa transformação socioeconômica no território, a terra em Goiás passou a ser adquirível através de firmamento de contratos de compra e venda, fazendo jus à Lei de Terras de 1850, abandonando o costume da posse para substituí-lo pela propriedade privada (RODRIGUES, 2005).

Sobre a distância do que a Lei de Terras (1850) previa e o que acontecia na prática social durante o século XIX especialmente, Martins (2018) explica que apesar da lei dispor sobre a propriedade privada ser onerosa, o regime sesmarial (o qual dispunha que a posse outorgada pela Coroa portuguesa validava o direito a terra, legitimado pelo trabalho desenvolvido nela) continuou norteando a maior parte das relações do humano com a terra no Brasil, pois o trabalho ainda continuou por muito tempo sendo a justificativa da propriedade, e não a aquisição onerosa. Segundo Martins (2018, p. 152):

embora o regime de sesmarias tenha cessado às vésperas da Independência e só tenha sido substituído por um novo regime fundiário com a Lei de Terras de 1850, ele continuou norteando as concepções de direito à terra de ricos e pobres e, em muitos casos, norteia até agora.

O fato de a Coroa portuguesa ser a real proprietária das terras e as ceder conforme seus critérios durante o regime das sesmarias revela que a propriedade até então não era concebida como uma propriedade absoluta e individual capitalista até a promulgação da Lei de Terras de 1850 no Brasil.

Smith (1990) relata que a promulgação da lei de Terras em 1850 foi um marco arbitrário, pois foi imposto conforme os interesses dos representantes das oligarquias agrárias (plantadores de café), o que aponta para a ocorrência posterior da transição entre propriedade não capitalista para capitalista, o que aconteceu bem depois da promulgação da Lei de Terras de 1850.

Tais apontamentos remetem ao pensamento de que a compreensão da propriedade privada não se deu apenas na implementação da Lei de Terras de 1850, e muito menos ocorreu de forma automática a ela, mas adveio de um processo histórico que teve o seu ápice somente no século XX, quando teve as relações sociais alteradas em decorrência da transição para propriedade capitalista por meio de alteração dos meios de produção que, por sua vez, colidiram com os incentivos governamentais e demais ações pessoais dos agentes públicos e privados. 


\section{A expansão da produção capitalista no campo em Goiás}

Ao tratar da expansão do modelo de produção capitalista no meio rural em Goiás, faz-se o uso do pensamento de Martins (2018), que identifica a existência de dois momentos para explicar essa expansão da Fronteira Agrícola: "frente de expansão" e "frente pioneira". O primeiro momento seria referente à expansão não capitalista sobre o território, referindo-se especialmente aos camponeses e índios, aqueles que não detinham nem a posse nem a propriedade da terra; e o segundo à expansão capitalista, através da atuação dos agentes modernizadores no território.

A frente de expansão se baseava na "economia do excedente", ou seja, o que ia para o mercado eram os produtos que excediam a produção de subsistência, devido a isso o preço dessas mercadorias era considerado pequeno (MARTINS, 1975). Miziara (2000, p. 8) destaca a ocorrência de duas características da frente de expansão, sendo elas: "o vazio demográfico e a especificidade da organização social”.

Quanto ao conceito de frente pioneira:

representa a incorporação de novas regiões à economia de mercado; ela se apresenta, assim, como fronteira econômica, isto é, como limite de avanço da dominação capitalista e sua característica é a instauração de empreendimentos econômicos, como "empresas imobiliárias, ferroviárias, comerciais, bancárias etc.; loteiam terras, transportam mercadorias, compram e vendem, financiam a produção e o comércio. (MARTINS, 1975, p. 45).

Martins (2018) considera que a frente pioneira é uma designação apropriada para tratar da chegada do novo, da modernização e dos moldes formatadores da economia de mercado. Tais inovações geraram transformações ambientais, econômicas e sociais derivadas dos novos meios de lida das pessoas entre si, com o capital e com o território.

A frente pioneira explicada por Borges (1990) diz respeito ao processo de ocupação do interior do estado de Goiás com o objetivo de promoção da produção capitalista. As áreas ocupadas não estavam até então inseridas na economia de mercado; a fim de que isso ocorresse foi necessária a implementação de infraestrutura que favorecesse essa conexão do Centro-Oeste com as demais regiões do país.

Borges (1990) trabalha com o conceito de modernização dependente, que foi desenvolvido por Fernandes (1973). Fernandes apud Borges (1990) explica que modernização dependente se trata do processo de modernização que foi imposto à determinada área em decorrência do avanço do sistema capitalista sobre ela; é uma forma de hegemonia. Em acordo com Borges (1990), afirma-se que em Goiás ocorreu tal processo de modernização dependente, pois a expansão da frente pioneira foi em grande parte incentivada por medidas estatais que influenciaram tal ocorrência através de políticas públicas específicas. 
Martins (2018, p. 74) relata que nas décadas anteriores à década de 1950, o Centro-Oeste e o Norte do país sofriam um processo "espontâneo de ocupação", o qual foi aumentado pelas ações do governo militar a partir da década de 1950 com o propósito de assumir o controle dessa ação de ocupação, canalizando-a para os fins de interesses econômicos expansionistas. A intenção era modernizar a produção rural e ocupar o território. Quanto à Amazônia, por exemplo, o lema do regime militar era “integrar para não entregar”.

A construção da Estrada de Ferro Goyaz, iniciada em princípios do século XX, foi essencial para o sucesso da expansão capitalista de produção, pois a terra por si não poderia atrair o capitalista, pois a expectativa do lucro era vinculada à presença da infraestrutura que permitisse o escoamento da produção. A ausência de um meio de transporte eficaz acrescido da pouca fertilidade do solo do Cerrado prejudicou a produção agropecuária em Goiás no século XIX, pois o escoamento da produção era difícil de efetuar, o que contribuiu para a existência "das relações de trabalho que desestimulavam a produtividade da mão-de-obra e a concentração da propriedade da terra" (BORGES, 1990, p. 52).

Dessa forma, pode-se perceber o quanto a presença de um meio de transporte como a ferrovia foi fundamental para o acréscimo do valor da terra em Goiás, favorecendo a economia e a transformação da produção agropecuária para um núcleo agroexportador nacional e, assim, atrativo aos olhos dos investidores. Para Morchon e Troster (1994 apud CAMPOS JÚNIOR, 2014, p. 72):

a terra pode ser entendida como um fator ou um recurso de produção. Logo, a terra, no momento em que se ampliam as condições de mercado em razão das expectativas criadas para o aumento de sua produção, torna-se mercadoria, sofrendo um processo de especulação e refletindo diretamente no comportamento de seu preço. Ou seja, a terra é um objeto físico, tornando-se mercadoria com a mudança nas relações sociais de produção.

A esse respeito, a pesquisadora Maria Amélia de Alencar (1993, p. 17 apud CAMPOS JÚNIOR, 2014, p. 74) afirma que "o preço de compra ou preço da terra nada mais é do que a renda da capitalização do solo, ou a compra do direito de auferir a renda”. Nesse contexto importante é citar Marx, que trabalhou a teoria da renda fundiária, classificando-a em renda diferencial I, que diz respeito à renda extraída da terra, devido às características naturais do solo, tais como localização, fertilização e distribuição de impostos; e renda diferencial II, que remete ao incremento de tecnologias que possibilitem o aumento da produção do solo, sem necessariamente o aumento da sua proporção territorial (MARX, 1984).

Silva, Moura e Campos (2016) afirmam que ao mesmo tempo que a ferrovia possibilitou o escoamento da produção, e por isso a integração do estado de Goiás às demais regiões do país, trouxe 
em seu bojo o acréscimo de valor às propriedades ${ }^{3}$ e mudanças ambientais na região, tais como a migração para essas localidades de fronteira. Nesse mesmo sentido, Oliveira (2012) dispõe que:

uma quarta onda migratória de famílias mineiras e paulistas que se deslocavam para Goiás e Mato Grosso. Nesta onda migratória estavam presentes também algumas famílias de sírio-libaneses que, gradativamente, foram se estabelecendo em Goiás [...] sempre acompanhando o traçado da estrada de ferro. (OLIVEIRA, 2012, p. 66).

Para Borges (1990), a Estrada de Ferro de Goiás foi um dos agentes modernizantes que contribuiu para a expansão capitalista da produção da região. Contudo, chama a atenção que a ferrovia não foi único agente, apesar de ser um dos principais responsáveis para a inclusão da região na economia agroexportadora. Segundo Martins (2018), as mudanças estruturais causadas pela expansão da frente pioneira sob o território foram realizadas pelos agentes da modernização que foram os "agentes da civilização" e "agentes da economia capitalista (mais do que simplesmente agentes da economia de mercado), de mentalidade inovadora, urbana e empreendedora" (MARTINS, 2018, p. 138).

Estabeleceu-se uma verdadeira guerra contra a natureza e batalha contra todos aqueles que representassem o atraso - como índios, comunidades quilombolas, o campesinato sem-terra, pequenos e médios proprietários tradicionais - que se encontravam pelo caminho para que se abrisse a passagem para a civilização e o progresso. Tudo isso apoiado e incentivado por agentes do Estado Republicano.

Da mesma forma que aconteceu em São Paulo a partir da segunda metade do século XIX, a expansão da Fronteira Agrícola estendeu-se para Goiás em princípios do século XIX com o avanço da ferrovia, que deu início a uma nova dinâmica de ocupação do território goiano por intermédio de incentivos governamentais. O Recenseamento Geral de 1920 (Vol. I, p. 278) já exaltava "os trilhos da Mogyana, que já se estendiam por Goyaz, os estão levando pelo mesmo caminho, trilhado pelos contemporâneos do Anhanguera [...] que já começam a invadir, de assalto, repelindo a mataria a golpes de machado e a tiros de carabina o bugre recalcitrante". Situação que teve maior amplitude, depois de 1930 pelas políticas públicas destinadas ao incentivo à colonização e migração, as quais foram responsáveis pelo preenchimento do espaço em questão e que foram alterando paulatinamente o modo de produção no campo a exemplo do que já havia ocorrido na região Sudeste do Brasil.

Os relatos do Recenseamento de 1920 (V. I, p. 378-380) exaltam a figura de dois agentes desse processo civilizatório: o bugreiro e o grileiro. O bugreiro era:

\footnotetext{
${ }^{3}$ Moraes e Costa (1987, p. 159) lecionam que: “a valoração capitalista do espaço é, antes de tudo, uma relação capital-espaço", ou seja, o consumo do espaço pelo capitalista gera a valorização deste, seja através do consumo produtivo (transformação dos recursos naturais em mercadorias) ou até mesmo do consumo improdutivo (no caso do arrendamento).
} 
o mameluco antigo assaltava para escravizar; o de hoje (1920), mas cruel e positivo, é meramente o exterminador: varre e limpa a floresta tropical da sua sevandijaria americana. Atrás dele vem o paulista moderno, tão ambicioso como o antigo e como este tenaz, arrastando a sua ruidosa e galharda "bandeira" de colonos italianos [...] o bugreiro vence o obstáculo material, que é o índio nômade, povoador infecundo da floresta fecunda. (RECENSEAMENTO GERAL DO BRASIL, v. I).

Já o grileiro, segundo relato apresentado no mesmo recenseamento, é aquele que vence o obstáculo jurídico, que é o direito à propriedade, pois

hoje (1920) ao contrário de outrora, não há terras sem dono: ou pertencem a particulares, como sobrevivência das imensuráveis sesmarias primitivas, ou são "terras devolutas" e pertencem, neste caso, ao Estado. Estas terras quando não pertencem ao Estado, se conservam inexploradas e virgens, mas "apropriadas" por latifúndios atrazadões, muito ciosos da grandeza dos seus latifúndios - "velhos barbaças que as detêm aos milheiros de alqueires para tirar delas um prato de feijão e uns porquinhos de ceva." [...] Ele é que vai dar ao colonizador progressivo, cheio de ambição e de capitais, o direito de explorar este tesouro infecundo. Para isto, cria pela chicana e pela falsidade, o indispensável titulo de propriedade. (RECENSEAMENTO GERAL DO BRASIL, v. I, p. 380).

Como afirmava Monteiro Lobato ${ }^{4}$, naquele tempo, o grileiro é que

opera as maiores falcatruas; falsifica firmas, papéis, sellos; falsifica rios e montanhas; falsifica o céu, a terra e as águas; falsifica Deus e o Diabo. Mas vence. Divididas as terras em lotes, vendem-nos os grileiros à legião de colonos que os seguem como urubus - pelo cheiro de carniça - Cinco, dez anos depois, a flor do café branqueia a zona e a incorpora ao patrimônio nacional. (RECENSEAMENTO GERAL DO BRASIL, v. I, p. 380).

Além desses agentes da "civilização" mencionados, outros fatores contribuíram para a valorização da terra ao longo do século $\mathrm{XX}$, associados ao implemento das novas tecnologias que, gradativamente, foram sendo implementadas no campo além da vontade individual dos principais agentes da modernização (MIZIARA, 2000). No quadro a seguir estão sintetizados os três momentos descritivos da expansão capitalista em Goiás.

QUADRO 1 - MOMENTOS DA OCUPAÇÃO DO CENTRO-OESTE

\begin{tabular}{|c|c|c|c|}
\hline Ocupação do espaço & Fase & Atividade principal & Época \\
\hline \multirow{2}{*}{ Frente de expansão } & $1^{\text {a Etapa }}$ & Ocupação pelo ouro & A partir dos anos 20 do século XVIII \\
\cline { 2 - 4 } & $2^{\text {a Etapa }}$ & $\begin{array}{c}\text { Ocupação do sul pelos } \\
\text { "Generalistas" }\end{array}$ & A partir do século XIX \\
\hline
\end{tabular}

${ }^{4}$ Monteiro Lobato. A onda verde, op. cit., p. 14. RECENSEAMENTO GERAL DO BRASIL, v. I, p. 380. 


\begin{tabular}{|c|c|c|c|}
\hline \multirow{2}{*}{ Frente pioneira } & $3^{\text {a Etapa }}$ & Estrada de Ferro & \multicolumn{1}{|c|}{ A partir da 1ª metade do século XX } \\
\cline { 2 - 5 } & $4^{\text {a Etapa }}$ & "Marcha para o oeste" & $\begin{array}{l}\text { A partir de 1930 com a construção de } \\
\text { Goiânia e criação da Colônia Agrícola } \\
\text { Nacional de Goiás -1941 }\end{array}$ \\
\hline Fronteira Agrícola & $5^{\text {a Etapa }}$ & Modernização da agricultura & $\begin{array}{l}\text { A partir de 1960 com a construção e } \\
\text { transferência da capital federal para Brasília }\end{array}$ \\
\hline
\end{tabular}

FONTE: MIZIARA (2005) apud RODRIGUES (2005, p. 29). Adaptado e revisado pela autora.

A partir da década de 1960, foi possível intensificar a produção no campo pelo uso de tecnologia disponibilizada pela Revolução Verde, que Rodrigues (2005, p. 25) conceitua como:

um movimento após Segunda Guerra Mundial que agrupou uma série de tecnologias que vinham sendo praticadas há algum tempo, dentre estas: Biológica (melhoramento genético), mecanização química (defensivos e fertilizantes), foi idealizado para permitir que a agricultura dos países em desenvolvimento aumentasse sua produção sem que fosse necessário mudar a estrutura da propriedade rural através da reforma agrária.

A tecnologia advinda da Revolução Verde e sua utilização na década de 1960 em diante possibilitou que o solo do Cerrado, antes considerado inapropriado para a produção agrícola de monoculturas, se transformasse em terra fértil e, assim, numa teia de possibilidades. $\mathrm{O}$ fator do relevo plano também atraiu a atenção dos produtores, tendo em vista a facilidade de locomoção de maquinários e tratores, favorecendo a mecanização do solo e aplicação de técnicas agrícolas como o cultivo permanente com usos de pivôs centrais (SANTOS, 2013).

A partir da década de 1960 em diante, autores como Martins (2018) tratam da expansão da produção capitalista em Goiás como "Fronteira Agrícola", a qual é desenvolvida melhor no próximo tópico.

\section{Fronteira Agrícola}

A partir do implemento de novas tecnologias para a produção rural na década de 1960, associado às políticas de financiamento e crédito rural, o estado de Goiás foi palco de um grande aumento produtivo que o colocou como um dos principais produtores e participantes da economia nacional (OLIVEIRA et al., 2011). Esse momento chamado de Fronteira Agrícola é sintetizado por Steinberger (2000, p. 37) da seguinte maneira:

- os anos 70, marcados pelo início da adaptação do cerrado à cultura da soja, quando chegaram os pioneiros dessa cultura ao Mato Grosso do Sul e foram instaladas as primeiras unidades de beneficiamento de grãos em Goiás;

- os anos 80, emblemáticos da expansão da soja e do milho, dominadas pelas tradings do mercado de commodities; 
- os anos 90, quando se assistiu à consolidação do complexo de grãos-carne com a participação de capitais internacionais e nacionais de grandes conglomerados do Sudeste e Sul do país.

Borges (2000), ao falar sobre a expansão da Fronteira Agrícola em Goiás, destaca que é primordial abordar a questão da desconcentração produtiva do Sudeste para o Centro-Oeste do país na década de 1970, propulsionada em grande parte por medidas estatais de incentivos para a modernização e colonização, bem como redução de impostos e possibilidades de crédito. Portanto, na década de 1970 houve a desconcentração produtiva e a desconcentração de infraestrutura de São Paulo para as zonas de fronteira, o que contribuiu para a modernização da produção e para a urbanização dessas regiões, como Goiás (SANTOS, 2013).

Cano (2008) ressalta que nas décadas de 1960 e 1970 o Brasil vivenciou o período chamado de "milagre econômico" sob a égide do governo militar, o qual diz respeito a uma política de crescimento econômico. A fim de conseguir essa meta, era necessário que se expandissem as fronteiras e, assim, aumentasse a produção com foco na exportação.

Becker e Egler (1998) explicam que a ambição dos governos militares nas décadas de 1960 e 1970 se concentrava no projeto "Brasil potência", que intencionava a inclusão do Brasil nos mercados internacionais com diversidade produtiva e incorporação de padrões modernos de produção, como maquinários e demais tecnologias disponíveis na época: "o programa para a modernização baseou-se também num projeto territorial fundado no ideário da integração nacional e do Brasil potência" (BECKER; EGLER, 1998, p. 136).

Essa expansão da produção capitalista não atingiu apenas o estado de Goiás, mas foi estendida às demais regiões do Brasil, o que levou a um "elevado crescimento do período que se manifestou em todos os setores produtivos, atingindo também a maior parte do território nacional e intensificou também o crescimento da urbanização e do emprego urbano" (CANO, 2008, p. 22).

A Fronteira Agrícola é dessa forma um conjunto de ações que se desenvolveu na história do país com a intenção de promover o preenchimento do espaço e aumentar a produção. Contudo, apesar das peculiaridades do solo do Cerrado, foi possível notar um resultado "satisfatório" a partir da década de 1970 em Goiás por contar com o apoio da tecnologia disponibilizada pela Revolução Verde e o implemento de tratores e demais máquinas, procedendo dessa forma à mecanização da produção (formação da agroindústria), esvaziamento dos campos e exigência de pessoal automatizado para o desempenho das funções antes desenvolvidas por qualquer sujeito iletrado que soubesse manusear a enxada. Nas palavras de Cano (2008, p. 44): “a expansão da pecuária e da moderna agricultura no Centro-Oeste, que dinamizaram a agricultura dessas regiões, dando azo a que mais tarde ali surgisse também uma agro industrialização e urbanização”. 
O movimento de modernização da produção rural gerou efeitos urbanos à medida que os sujeitos removidos de seus empregos rurais habituais através de sua substituição pelo uso da tecnologia, migraram para as cidades, forçando de certa forma a urbanização. Dessa maneira, é possível falar que a Fronteira Agrícola alcançou mais do que os limites das propriedades rurais, mas toda a dinâmica social do estado. Segundo Santos (2013, p. 11): “o campo brasileiro moderno repele os pobres e os trabalhadores da agricultura capitalizada vivem cada vez mais nos espaços urbanos".

Os grandes incentivadores desse processo de expansão da Fronteira Agrícola foram os agentes financeiros (BORGES, 2000), ou seja, os bancos e demais investidores capitalistas. Para Santos (2013), tais decisões de investimento em mecanizar o território e favorecer o acesso à tecnologia que visa aumentar a produção rural são de cunho geopolítico, pois defende a ideia de que o mercado por si fornece meios de transformações do território a fim de reproduzir o capital. O Estado, dessa forma, trabalharia para favorecer o mercado e os agentes financeiros.

Em contraponto, Miziara (2000, p. 286) dispõe que na década de 1970: “a existência de tecnologias adaptadas e infraestrutura adequada não foram suficientes para despertar o interesse de investidores do Sul; foi necessário que o Estado fornecesse outros atrativos, principalmente em termos de crédito e de acesso a custo baixo a terra". Tal ideia difere dos demais por atribuir especial destaque à escolha dos agentes individuais no processo de ocupação do território pela Fronteira Agrícola, pois o autor considera que apenas o acesso à tecnologia ou aos incentivos governamentais não foram fatores suficientes para a análise da expansão desse processo, mas há a forte participação dos agentes individuais que cooperaram nesse processo através das suas escolhas, e por isso devem ser levados em conta ao tratar do assunto.

Miziara (2000) parte do princípio individualista metodológico para formular seu modelo de compreensão acerca da Fronteira Agrícola em Goiás. Esse apontamento é usado como crítica ao marxismo tradicional, pois Elster (1989) apud Miziara (2000) aponta falhas na metodologia marxista para analisar situações como a expansão da Fronteira Agrícola. Uma dessas fraquezas metodológicas consiste na distância temporal entre a formulação da metodologia marxista e a época presente. Outro problema é o holismo metodológico, pois nele atributos essencialmente individuais acabam por ser atribuídos a entidades coletivas.

Dessa maneira, Miziara (2000) elabora um modelo de análise que contempla o contexto individual dos agentes envolvidos na transformação do espaço pela expansão da Fronteira Agrícola em Goiás:

fatores macro, como intervenção estatal, desenvolvimento das forças produtivas, mudança na base tecnológica etc. criam condições para a ação do capitalista individual. Entretanto, esses fatores macro por si só não garantem a ocorrência de novas aplicações de capital, sendo necessário para compreender o processo perceber 
os elementos que fazem com que os capitalistas individuais tomem a decisão, ou não, de aplicar seus recursos em outros locais. (MIZIARA, 2000, p. 286).

Percebe-se, assim, que a expansão da Fronteira Agrícola deixa de ser um assunto estritamente rural para um tema mais complexo e amplo, tendo em vista as profundas alterações que esse movimento de expansão promove no território. Em Goiás, a partir do aumento da produção propiciado pelas tecnologias e maquinários na década de 1970, outros setores da sociedade se desenvolveram, tais como o parque industrial, "a consolidação estrutural de logística, tais como a Ferrovia Norte-Sul, o Porto Seco do Centro-Oeste e a futurística Plataforma Logística Multimodal" (OLIVEIRA et al., 2011, p. 13).

Programas como Fomentar (1984) e Produzir (2000) foram fundamentais nesse processo de crescimento produtivo e expansionista no território goiano (CASTRO; CASTRO, 2012). As políticas estatais passaram a ser integradas rumo ao progresso prometido pelo desenvolvimento econômico advindo em primazia desse momento de Fronteira, culminando na atual situação do estado de Goiás diante do quadro nacional.

Segundo a tabela fornecida pelo Instituto Mauro Borges $(2017)^{5}$, Goiás se encontra como o sexto colocado em um ranking nacional de participação no valor adicionando bruto a preço básico na agropecuária, nono em indústria e décimo em serviços no ano de 2014. Já o Centro-Oeste se encontra como terceiro na agropecuária, quarto em indústria e serviços.

A partir da tabela é possível perceber a notável importância do setor agrário para a economia do estado de Goiás e que relativamente há pouco tempo atrás o estado era considerado improdutivo em decorrência das características naturais do solo e clima, mas percebe-se o crescimento desse setor e notoriedade em cenário nacional.

A expansão da Fronteira Agrícola modificou o modo do ser humano lidar com a terra, a forma de o Estado tratar os investidores e os moldes do próprio território em questão. Umas das alterações importantes fomentadas por essa expansão é a valoração da terra, que teve diferentes resultados no estado de Goiás após o implemento da tecnologia e, assim, consequente aumento da produção do campo.

\section{Valoração da terra}

O preço da terra é assunto discutido pelos economistas David Ricardo (1772-1823) e Karl Marx (1818-1883) desde o século XIX. Segundo Ricardo (1996), a renda proveniente da terra, chamada então de renda diferencial, é aquela que diz respeito à fertilidade do solo e à distância do centro consumidor. Por sua vez, Marx (1984) entende que a renda da terra leva em conta o fator da

\footnotetext{
${ }^{5}$ Constitui a publicação mais recente do Órgão.
} 
utilização da tecnologia, a qual pode alterar as condições naturais primárias do solo. Adam Smith, na sua obra $A$ riqueza das nações, publicada originalmente em 1776, segundo (CAMPOS JÚNIOR, 2014, p. 74)

explica que a renda da terra aumenta em função da boa qualidade das pastagens, acabando o proprietário por reduzir a presença da mão de obra em sua propriedade, além de manter seu gado em uma área menor, com reflexos diretos em seus custos de produção. Quanto à localização da propriedade, o autor afirma que quando estas estão mais distantes a sua taxa de lucro é geralmente menor do que nas proximidades das grandes cidades.

Quanto à Goiás, seguindo a perspectiva dos clássicos da economia política, Ferreira, Miziara e Ribeiro (2007, p. 50) afirmam que: "no caso do Cerrado brasileiro, em especial do Centro-Oeste, a formação do preço da terra rural foi particularmente influenciada pela articulação do binômio condições naturais e tecnologia". Para a devida compreensão da questão do valor da terra em Goiás, apresenta-se o modelo de Miziara (2000), que por sua vez recorre a Marx (1986) para explicar a renda fundiária e sua influência na ocupação do espaço. Para Miziara (2000, p. 11): "a renda fundiária pressupõe a extração de um sobrelucro, que é destinado ao proprietário da terra". Sobre a renda fundiária, Martins (2018, p. 75) a reconhece como um "bloqueio" para a propriedade porque o preço da terra "representa uma dedução do capital propriamente dito, diminuindo a quantia disponível para o investimento produtivo, um investimento propriamente capitalista".

Borba (2011) identifica como renda diferencial 1: "aquela derivada das características naturais, tendo como variáveis os seguintes elementos: localização e fertilidade; distribuição de impostos; desenvolvimento diferenciado da agricultura e desigualdade na distribuição de capitais". (BORBA, 2011, p. 27). De acordo com essa ideia, a propriedade lotada com terra fértil apresentará uma renda mais alta. Já a renda diferencial 2, segundo Miziara (2000, p. 11), diz respeito à "massa de capital idêntico aplicada na mesma parcela de terra, gera resultados diferentes”. Ou seja, seguindo a concepção já apresentada pelos clássicos da economia política, especialmente David Ricardo e Karl Marx, Miziara "entende que a renda da terra é derivada da fertilidade natural do solo e da distância desta dos centros consumidores. Levando-se em consideração, também, a influência do uso de tecnologia no solo, o que costuma modificar suas condições naturais de fertilidade" (CAMPOS JUNIOR, 2014, p. 75, grifo nosso).

A partir dessa exposição, entende-se que a ocupação do espaço é ligada à expectativa do sobrelucro, o que explica a questão de terras localizadas num mesmo estado apresentarem preços diferentes. O que faz com que propriedades contidas no mesmo espaço apresentem diferentes valorações são fatores tais como a localização, o acesso a transportes e o uso de tecnologias sobre aquele espaço (REZENDE, 2002). Ou seja, as análises da expansão da fronteira agrícola em Goiás 
contribuíram não apenas para a modificação da relação com a terra, que foi sendo ocupada de forma mais intensiva, mas consolidou a concepção de propriedade individual e absoluta que foi deixando de ser apenas um domínio patrimonial controlado pelas tradicionais famílias oligárquicas que, de certa forma, "garantiam" o acesso de usufruto da terra às famílias campesinas tradicionais assentadas em relações sociais de trabalho não assalariadas baseadas no compadrio e na camaradagem. Enquanto a maior parte da população brasileira vivia no campo o acesso a terra era um pré-condição básica de sobrevivência, especialmente de famílias tradicionais campesinas. Situação que foi se modificando com o avançar da Fronteira Agrícola em Goiás iniciada a partir dos fins década de 1960, quando acabaram sendo "expulsas" do campo sem garantias de acesso a terra, que foram se tornando cada vez mais difíceis e menos ainda do direito à propriedade da terra para poder trabalhar e viver no campo.

Os investidores geralmente buscarão lugares que apresentem maiores chances de reproduzir o capital e de gerar lucros. No caso de Goiás, a expansão da Fronteira Agrícola, possibilitada pela soma de fatores já abordados, favoreceu a valorização da terra em determinadas localidades do estado devido ao fato da terra ter sido melhorada pelo uso de tecnologia e transpassada por meios de transportes e demais infraestruturas que conectaram o espaço em questão aos principais mercados consumidores.

Borba (2011) entende que a ocupação do estado de Goiás pela expansão da Fronteira Agrícola guarda estreita ligação com o preço da terra, localização dos mercados consumidores e investimentos de capital em tecnologia. $\mathrm{Na}$ visão dele, os maiores investimentos acontecem nas regiões com terras mais valorizadas, ou seja, nas regiões com mais infraestrutura como estradas, frigoríficos, próximos de centros industriais. Borba (2011, p. 27) afirma que: "a expansão da agricultura valoriza o preço da terra”. Os resultados apresentados por algumas pesquisas atestam que nas regiões sul, sudeste e sudoeste de Goiás ocorreu um processo de valorização da terra a partir da chegada dos trilhos da Estrada de Ferro Goyaz. Segundo Borges (1990, p. 79):

Em Ipameri vendia-se um alqueire de mata em 1915 a 50\$000. Com as transformações da economia agrícola do município e o aumento da imigração, a terra de mata própria para cultura era, em 1920, vendida até a 300\$000 o alqueire, valorizando-se assim, 600\% em apenas 5 anos.

O mesmo pode ser percebido na cidade de Anápolis. Segundo Campos Júnior (2014, p. 80), “de 1898 a 1911, o preço do alqueire de terra de campo aumentou, nominalmente, em até 500\%. Entre 1911 e 1918, a variação foi superior a 566\%. A valorização e o comércio de terras já eram percebidos, também, no sul de Goiás, embora relativamente distantes das estações ferroviárias,

Segundo notícias veiculadas pela Revista Informação Goyana, em 1929, fazendas que 
foram adquiridas por cinco, seis ou dez contos de réis hoje (1929) são vendidas por cem, duzentos e até mais de 300 contos de réis. [...] no sul de Goiás, parte em que o progresso se intensifica [...] as terras de cultura já atingiram elevadíssimo preço. Em Bela Vista, por exemplo, arrendam-nas nas portas da cidade a 1:500\$000 o alqueire, sendo que as vendas se realizam a 2:000\$000 (A INFORMAÇÃO GOYANA, v.12, n. 7, ano 13, p. 1345, fev. 1929).

Em Morrinhos, no sul de Goiás, em 1927, segundo relatos de João de Minas, as terras de cultura eram comercializadas na média de 500 mil réis o alqueire, enquanto as de campos na média de 100 mil réis. Em Pouso Alto (Piracanjuba), as terras de cultura próximas à cidade chegavam a ser comercializadas por $1.000 \$ 000$ contos de réis e em áreas mais afastadas por 200 mil réis o alqueire. Em Santa Rita do Paranaíba (Itumbiara), em um raio de sete léguas da cidade, o alqueire de terras de cultura custava em média 500 mil réis e de campos 100 mil réis. Nas localidades mais afastadas das cidades e das estradas de rodagens, as terras de campos chegavam a ser vendidas por até 50 mil réis e as de cultura 250 mil réis o alqueire. ${ }^{6}$

No final da década de 1920, segundo Altamiro Pacheco, já havia certa intensificação dos negócios; a produção agropastoril, da indústria e do comércio era evidente em vários municípios, não apenas nos atravessados pelos trilhos da Estrada de Ferro Goiás, predominando um clima de grandes expectativas que atraía um fluxo migratório considerável de mineiros e paulistas movidos pelo "entusiasmo que domina o espírito dos que mourejam em Goiás para com os negócios de terras. Compras e vendas se multiplicam" (A INFORMAÇÃO GOYANA, v. 12, n. 7, ano 13, p. 1345, fev. 1929, grifo nosso).

Da mesma forma, o avançar da Estrada de Ferro Noroeste do Brasil no Mato Grosso, apenas no município de Campo Grande, segundo Campos Júnior (2014, p. 82, grifo nosso) fez "o preço de uma légua quadrada de terra (3.600 ha) aumentar, em alguns casos, em 400\%, passando de oito contos de réis para quarenta contos".

Mesmo com a presença da Estrada de Ferro Goyaz, na primeira metade do século XX, segundo Campos Júnior (2014, p. 79), nas regiões muito afastadas da ferrovia, especialmente, ao norte de Goiás:

a terra pouco valia nas áreas "periféricas" do próprio estado e seu rendimento era pequeno em termos comerciais, embora no sul goiano a terra evidentemente valesse mais face a uma maior identificação da região com os trilhos da ferrovia. [...] persistia o domínio da grande propriedade rural em poucas mãos e uma nítida separação campo-cidade, na qual os proprietários residiam nas próprias fazendas, rejeitando o absenteísmo: apenas cerca de $2 \%$ dos estabelecimentos agropecuários de todo o estado eram conduzidos por administradores ou arrendatários.

\footnotetext{
${ }^{6}$ Informações extraídas do Álbum Brasileiro - Progresso maravilhoso do torrão goiano, publicação avulsa editada por João de Minas no ano de 1927.
} 
Toda a conjuntura da economia nacional contribuiu para a ocupação do estado de Goiás. Oliveira (1980) identifica os movimentos nacionais de expansão da Fronteira Agrícola iniciada, sobretudo, a partir da marcha do café e da desconcentração produtiva do Sudeste, alargando as fronteiras que antes separavam Goiás do restante do núcleo produtivo do país.

Outro aspecto inegável foi que em Goiás as cidades não contempladas diretamente com entroncamentos ferroviários como Morrinhos, Caldas Novas, Itumbiara, Rio Verde e Jataí, localizadas no sul e sudoeste de Goiás, a partir de fins da década de 1910, começaram a se organizar na implementação das primeiras rodovias de circulação de automóveis - inclusive, carroçáveis - para o transporte de passageiros e cargas, interligando esses municípios à Estrada de Ferro Goiás localizada em Catalão e Ipameri, e à Estrada de Ferro Mogyana localizada nos municípios de Araguari e São Pedro de Uberabinha (atual Uberlândia), no Triângulo Mineiro. Segundo França (1981, p. 16, grifo nosso):

no sul de Goiás [...] obras de infraestrutura foram construídas para a melhoria dos meios de comunicação e transportes. Em 1909, inaugurou-se a ponte do Cahidor, no Rio Paranaíba, distante três quilômetros do núcleo urbano de Santa Rita do Paranaíba. Em 1917, a cidade se ligava a Uberabinha (Uberlândia) por uma estrada de rodagem de 24 quilômetros de percurso. Tais melhoramentos nos meios de circulação deram grande impulso à função tradicional de intermediação comercial exercida por aquele centro.

A “marcha para o oeste", política estatal de ocupação do Centro-Oeste promovida durante o governo Vargas, contribuiu para, de certa forma, em algumas localidades, acelerar a urbanização de Goiás. Cooperou muito para a valorização da terra em Goiás fatores como: a construção de Goiânia em 1933, a transferência da capital do país para Brasília em 1960, a criação da Superintendência de Desenvolvimento do Centro-Oeste (Sudeco) em 1967, o estabelecimento do eixo Goiânia-Anápolis-Brasília, sendo ações desenvolvidas pelo Estado a fim de promover o desenvolvimento da região (SANTOS, 2013).

Especificamente quanto ao estado de Goiás, Ferreira, Miziara e Ribeiro (2007), após a análise dos diferentes preços da terra nas regiões do estado, concluíram que:

O preço das terras com pastagens ou agricultura possui preço máximos variando de $\mathrm{R} \$ 7.400,00$ a $\mathrm{R} \$ 12.900,00$ por hectare, o preço máximo de terras com vegetação remanescente é de cerca de $\mathrm{R} \$ 4.630,00$, ou seja, com valor de $36 \%$ a $64 \%$ a menos que as áreas transformadas para finas agrícolas e criação de rebanhos. Isso indica que a antropização privilegia as áreas com melhores condições de geração de renda, uma vez que o preço expressa justamente essa capacidade. Assim, as áreas ainda não antropizadas são aquelas com piores condições produtivas. (FERREIRA; MIZIARA; RIBEIRO, 2007, p. 59).

Dessa forma, tem-se em um primeiro momento a ferrovia e depois estradas de rodagens interligando a capital e demais regiões do estado de Goiás com todas as demais regiões brasileiras, o 
que possibilitou a valorização da terra à medida que esta foi sendo ocupada pela pecuária e lavoura intensiva. Nesse processo, a expectativa de lucro começou atrair a atenção de personagens como os grileiros que Silva, Moura e Campos (2016, p. 279) chamam de "fenômeno social", que foi bem evidente entre 1940 e 1950, agindo dentro do que Martins (2018) denomina como frente pioneira. Percebe-se que o valor da terra em Goiás foi elevado à medida que a terra se mostrou apta à produção e ao escoamento. A terra não valia mais por si, mas pelo que poderia vir a ser (BORGES, 1990).

\section{Consequências da expansão capitalista para o bioma Cerrado em Goiás}

A princípio, acerca da questão fundiária é importante ressaltar que o avanço do capitalismo trouxe severas consequências para os sujeitos que lidavam com a terra, anteriormente em um regime de relação não capitalista de compra e venda, mas de uso. As mudanças estruturais na apropriação legal da terra através da compra e venda causaram conflitos pela terra derivados de ocupações que contrastavam com as afirmações de poder de grupos dominantes, manifestadas através de violência no campo (OLIVEIRA, 1980).

Nesse cenário de transformação das formas de produção em si e, portanto, também da maneira do ser humano lidar com a terra, surgiram personagens que atuavam no contexto de negociação da terra. Não eram nem posseiros, nem produtores, mas chamados de grileiros, sujeitos que atuavam negociando a terra através de títulos falsos, atuando na região Centro-Oeste na mesma época que se deu a valorização da terra em decorrência das alterações produtivas no campo (MARTINS, 2000).

A terra em Goiás foi espaço de muita disputa e injustiça: "no processo de ocupação, foram muitas as formas utilizadas por diferentes grupos para se estabelecerem na terra. $\mathrm{O}$ que chama a atenção nessas ocupações foram os recursos e meios utilizados pelas elites dominantes para controlar a terra e impedir o trabalhador de ter acesso a ela" (SILVA; MOURA; CAMPOS, 2016, p. 279).

O que mostra que Martins (2000) tem razão em afirmar que as elites agrárias dominantes são quem de fato detêm o poder no Brasil, pois em Goiás os sujeitos do campo foram expropriados do uso da terra através da imposição da condição legal de aquisição onerosa da propriedade privada, tendo dificultado seu acesso ao meio de produção. Tal fator colocou os sujeitos em situação de fronteira em circunstâncias de conflito com interesses capitalistas.

Segundo Silva, Moura e Campos (2016, p. 275): “as questões agrárias e o processo de ocupação territorial em Goiás no século XX tiveram como característica marcante a dificuldade do acesso à propriedade pelos mais pobres". O que os autores consideram como a causa dessa situação crítica da problemática fundiária em Goiás no século XX é a distância entre a legislação e a prática social, pois a Lei de Terras de 1850 evidenciava a proibição do apossamento de terras, no entanto, a 
classe mais favorecida o fazia livremente, cooperando para a intensa desigualdade distributiva na região. Além disso, as migrações promovidas na "marcha para o oeste" na década de 1930 trouxeram migrantes pobres que ocupavam pedaços de terra em Goiás, mas sem assegurar o devido registro legal que garantisse o direito à propriedade.

A ocupação das terras goianas sem registro geraram inúmeros problemas de ordem prática, pois a Lei de Terras de 1850 previa prazos para acontecer a regulamentação, que muitas vezes não eram cumpridos e prejudicavam a fiscalização do estado no sentido de acompanhar a real situação das terras ocupadas (SILVA; MOURA; CAMPOS, 2016). Essa dificuldade de acompanhamento estatal das ocupações da terra contribuiu para a atuação dos grileiros, favorecendo a intensificação dos conflitos e da violência no campo na região do estado de Goiás. Isso permite afirmar que uma das consequências da expansão capitalista sobre o território é a presença da violência no campo, pela ocorrência desse processo de grilagem de terras.

Outra consequência é relacionada com o meio ambiente, especificamente com o bioma Cerrado, que sofreu danos significativos no decorrer dos anos. Segundo Sano et al. (2008, p. 155):

As duas classes mais representativas de uso da terra, isto é, as pastagens cultivadas e as culturas agrícolas, ocuparam 26,5 e $10,5 \%$ do Cerrado, respectivamente, e apresentaram distribuição espacial bastante heterogênea na região de estudo. As áreas mais extensas de uso da terra foram encontradas na porção sul, enquanto a maior parte da vegetação natural localizou-se na porção norte. Esse retrato é fruto do próprio histórico de ocupação das terras do Brasil.

Essa citação de Sano et al. (2008) é resultado de uma pesquisa realizada através de mapeamento da região Centro-Oeste, onde se detectou as formas de uso da terra, demonstrando o quanto o processo de ocupação territorial está atrelado ao desmatamento e à transformação do espaço do Cerrado de forma geral, incluindo outros estados, além de Goiás, que compõem a região Centro- Oeste. Segundo Sano et al. (2008), as características naturais do Cerrado, por exemplo o fato do relevo ser plano, aliado com a implantação de infraestrutura, contribuíram para que cerca de $40 \%$ da área desse bioma fosse transformada em áreas de pastagens, agricultura e urbanização entre as décadas de 1970 e 1990.

Rocha et al. (2011, p. 343) afirmam que "várias são as formas de mudanças na cobertura da vegetação passíveis de detecção por dados satelitários: perda de biomassa causada por desmatamento, queimadas, perda de folhagem devido às estações climáticas ou estresse hídrico”. Sobre isso, o estudo realizado por Andrade et al. (2017, p .40), publicado em 2017, aponta que: "173 municípios (dos 806 analisados) do Cerrado brasileiro estão com mais de 50\% de suas pastagens cultivadas sob algum processo de degradação". Sabe-se que o Cerrado ultrapassa os limites do estado de Goiás, abrangendo ainda Bahia (BA), Distrito Federal (DF), Maranhão (MA), Mato Grosso (MT), Mato 
Grosso do Sul (MS), Minas Gerais (MG), Pará (PA), Paraná (PR), Piauí (PI), Rondônia (RO), São Paulo (SP), Tocantins (TO). Dessa forma, no que toca especificamente ao estado de Goiás: "há indicativos de degradação em mais de 50\% da área total de pastagens cultivadas em vários municípios das regiões oeste, centro, noroeste e norte de Goiás” (ANDRADE et al., 2017, p. 36).

O mapa a seguir, feito em 2014, representa a vulnerabilidade ambiental do estado de Goiás. O estudo disponibilizado pela plataforma SIEG-Mapas demonstra os impactos ambientais decorrentes da exploração dos recursos naturais de forma intensiva, como tem sido feito durante as últimas décadas.

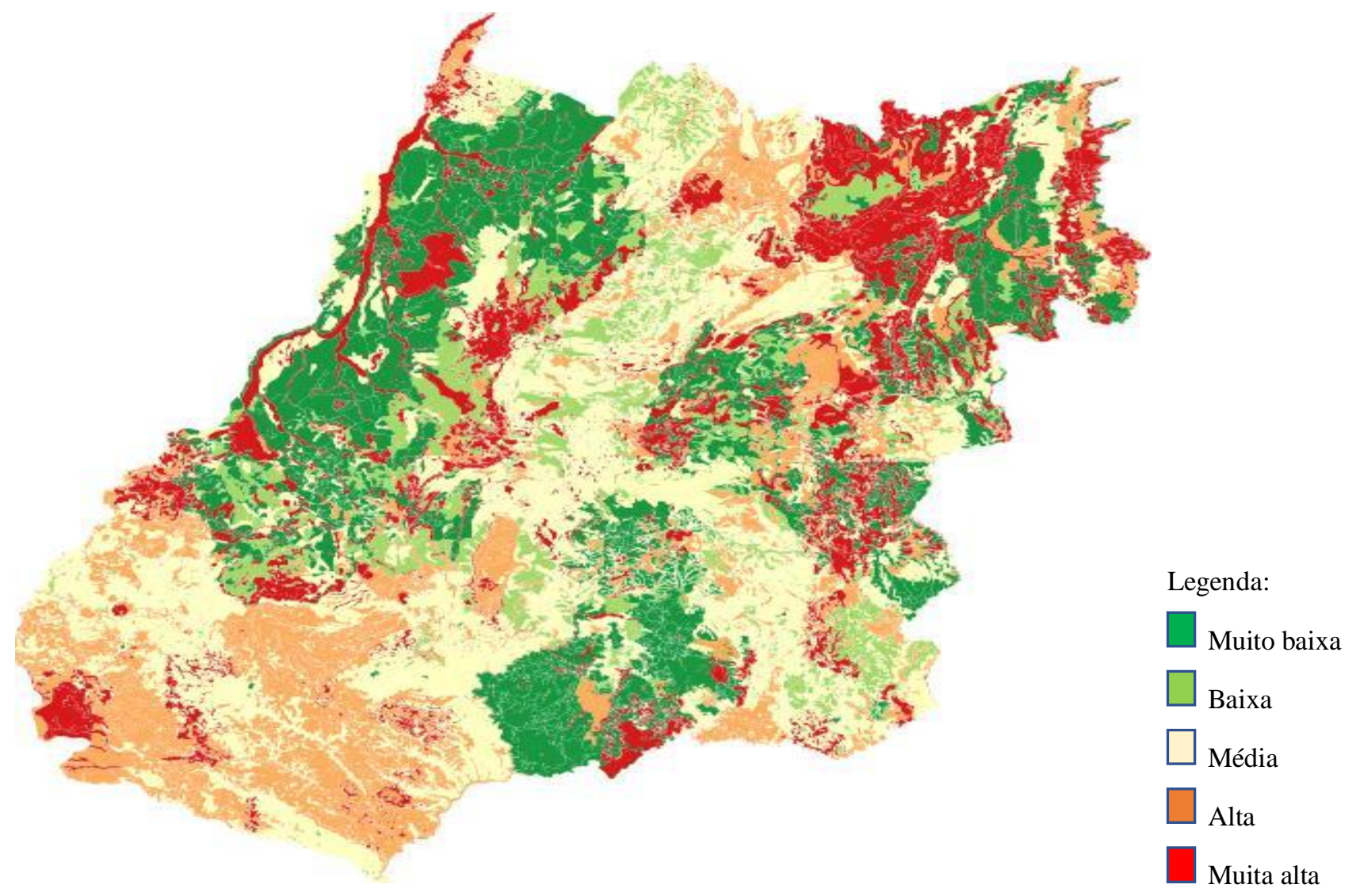

FONTE: SIEG-MAPAS. ${ }^{7}$

A partir das informações do mapa, é possível notar que as regiões: norte, noroeste e oeste do estado de Goiás apresentam maiores porções de biodiversidade, enquanto as regiões nordeste e sudoeste demonstram estar com a vulnerabilidade ambiental muito alta, alta e média. A região sul tem uma parte de vulnerabilidade muito alta, mas também apresenta outra parte de vulnerabilidade

\footnotetext{
${ }^{7}$ Mapa de Vulnerabilidade Ambiental do estado de Goiás. Produtos do Macrozoneamento Agroecológico e Econômico do estado de Goiás. Fonte: MACROZAEE - SICAM/SEMARH/SEAGRO. Escala: 1:1.000.000. Gerado em: 26 jun. 2014.
} 
muito baixa. O sudeste goiano oscila entre vulnerabilidade média e alta. A região do entorno de Brasília demonstra vulnerabilidade média, alta, muito alta, baixa e muito baixa. A região metropolitana de Goiânia e centro goiano apresentam em sua maior parte média vulnerabilidade ambiental.

É possível notar que as regiões nordeste, sudeste e sudoeste goiano apresentam maior nível de degradação e, consequentemente, maior vulnerabilidade ambiental, em contraste com as regiões norte, oeste e noroeste do estado de Goiás, que resguardam maior parte do cerrado preservado; ainda, é notável perceber que as regiões contempladas pela ferrovia apresentam entre baixa, média, alta e muito alta vulnerabilidade ambiental, conforme a Figura 2.

\section{FIGURA 2 - TRECHO FERROVIÁRIO DE GOIÁS (2017)}

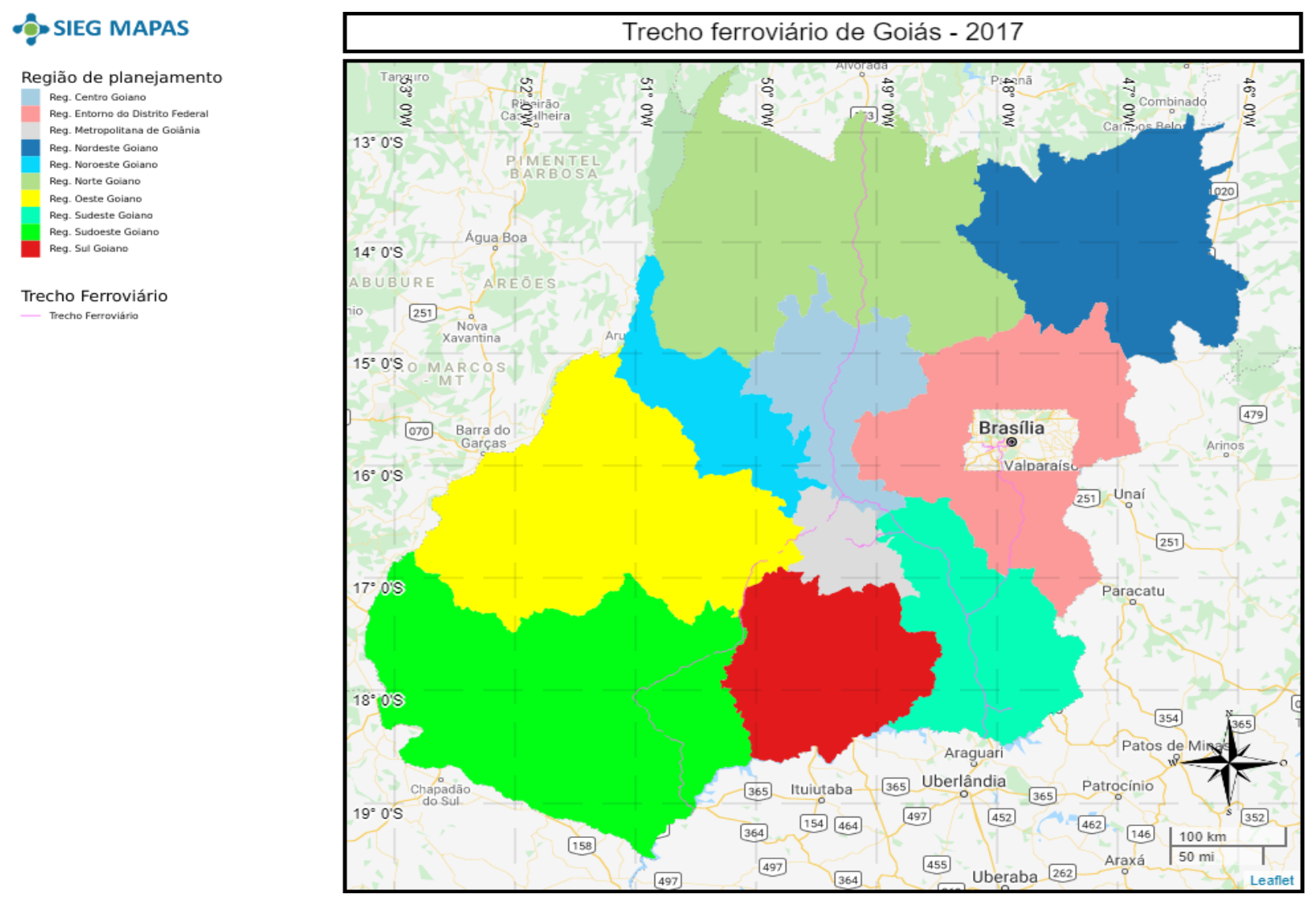

FONTE: SIEG-MAPAS ${ }^{8}$

Em pesquisa divulgada em 2019 pelo Instituto Mauro Borges e Secretaria de Estado da Economia de Goiás, foram listados os dez maiores municípios produtores agropecuários do estado em 2017, sendo que 6 deles estão na região sudoeste: Rio Verde, Jataí, Mineiros, Montividiu,

\footnotetext{
${ }^{8}$ A classe Trecho Ferroviário faz parte da categoria Sistema de Transportes da Base Cartográfica Contínua das Unidades da Federação Goiás e Distrito Federal, na escala 1:100.000. Fonte: IBGE, Base Cartográfica vetorial contínua do Estado de Goiás e do Distrito Federal (BC100/GO_DF). Geração em 28/04/2017.
} 
Quirinópolis e Chapadão do Céu. As outras quatro cidades estão nas regiões: entorno de Brasília: Cristalina; oeste: Paraúna; sul: Goiatuba, Itumbiara; e sudeste: Catalão. Segundo a pesquisa, que tratou de medir o PIB dos municípios goianos no ano de 2017, “Em 2017, os dez municípios com maior participação na agropecuária representaram 31,5\% da renda gerada por esse setor”. Segundo o estudo, 77 municípios goianos têm como atividade principal a agropecuária (IMB, 2019, p. 14).

\section{Considerações finais}

Martins (1975) ressalta que o que define a implementação do capitalismo no campo não é somente a transformação das relações sociais em troca e venda, mas essencialmente a transformação da terra em mercadoria, sendo a propriedade privada um importante marco de análise dele e assim sendo, é replicada essa ideia nesta pesquisa, pois se entende que a partir da transformação da terra em mercadoria, fomentada pela implantação de padrões produtivos tecnológicos, mudanças estruturais foram promovidas na sociedade.

Ou seja, apenas a implementação da Lei de Terras de 1850 não foi suficiente para alterar a dinâmica social da época, que foi sendo modificada com o processo de capitalização da terra. Nesse sentido, a Lei de Terras se configura como um marco processual de transformação da terra em mercadoria, pois a partir de sua edição houve a necessária normatização que regulamentasse tais procedimentos de compra e venda. Contudo, é importante observar que ocorreu um lapso temporal na adaptação social até que fosse totalmente aplicada, como se observou na história de Goiás.

A prática social, portanto, foi alterada no processo de lida com a terra como mercadoria a partir dos fins do século XIX com a chegada dos trilhos das estradas de Ferro Mogyana no Triângulo Mineiro e Estrada de Ferro Goyaz no território goiano em 1913. Mas o processo de mercantilização da terra e consolidação como propriedade absoluta se deram ao longo do século XX com a construção de Goiânia e, principalmente, em 1960 com a transferência da capital federal para Brasília, quando de fato ocorreu o acelerar do processo de incorporação do Cerrado à economia nacional e internacional com a modernização no campo. A partir disso, toda a dinâmica territorial foi se amoldando ao modelo capitalista, passando o espaço por transformações ambientais e sociais como a urbanização e o aumento significativo da produção no campo, passando a constituir-se um dos principais estados do Brasil nesse segmento de produção rural.

As mudanças geraram consequências para o espaço, tais como a valoração da terra, a migração dos agentes modernizantes, a atuação dos grileiros e a perda considerável da biodiversidade do Cerrado, o que compromete a qualidade ambiental e gera a necessidade de mais estudos e políticas 
públicas que visem minorar os danos e incrementar o progresso econômico de forma que seja mais distribuído e menos lesivo ao meio ambiente.

\section{Referências}

ANDRADE, R. G. et al. Avaliação das condições de pastagens no cerrado brasileiro por meio de geotecnologias. Revista Brasileira de Agropecuária Sustentável (RBAS), Viçosa, v. 7, n. 1 p. 34-41, 2017.

ARANHA, M. L. de A.; MARTINS, M. H. P. Filosofando: introdução à Filosofia. São Paulo: Moderna, 2009.

BECKER, B.; EGLER, C. Brasil: uma potência regional na economia-mundo. Rio de Janeiro: Bertrand Brasil, 1998.

BORBA, A. O. S. Expansão de fronteiras e intensificação da pecuária. 2011. Dissertação. Mestrado em Agronegócio, Universidade Federal de Goiás, Goiânia.

BORGES, B. G. O despertar dos dormentes: estudo sobre a Estrada de Ferro em Goiás e seu papel nas transformações das estruturas regionais:1909-1922. Goiânia: UFG, 2000.

BORGES, B. G. Goiás nos quadros da economia nacional: 1930-1960. Goiânia: Cefrag, 1990.

BORGES, I. M. Estado de Goiás: Regiões de Planejamento (2006). Goiânia: Secretaria de Planejamento e Desenvolvimento do Estado de Goiás, 2006. Disponível em: https://www.imb.go.gov.br/files/docs/publicacoes/regioes-planejamento/regplan2006.pdf. Acesso em: 08 jul. 2020.

BORGES, I. M. PIB dos municípios goianos 2017. Goiânia: Secretaria de Estado da Economia, 2019. Disponível em: https://www.imb.go.gov.br/files/docs/publicacoes/pib-municipios/pibmun2017.pdf. Acesso em: 08 jul. 2020.

BUCKINGHAM, W. et al. (Org.). O livro da Filosofia. São Paulo: Globo, 2011.

CAMPOS JÚNIOR, P. B. A locomotiva nas fronteiras: o veículo das transformações em Goiás 1913-1940. 2014. Tese (Doutorado) - Universidade Federal de Goiás, Instituto de Estudos Socioambientais, Goiânia. Disponível em: https://repositorio.bc.ufg.br/tede/handle/tede/3596. Acesso em: 09 out. 2018.

CANO, W. Desconcentração produtiva regional do Brasil 1970-2005. São Paulo: UNESP, 2008.

CASTRO, M. C. G. de; CASTRO, A. C. de Política Industrial como Política de Desenvolvimento em Goiás: A construção de uma região. In: I SEMINÁRIO SOBRE POLÍTICAS E ASPECTOS DAS MUDANÇAS INSTITUCIONAIS NO BRASIL E EM GOIÁS, 1, 2012, Anápolis. Anais. Anápolis: UEG, 2012. p. 68-74. Disponível em: http://www.bibliotekevirtual.org/simposios/2316-8307/2316-8307-a009.pdf. Acesso em: 27 jun. 2018. 
FERREIRA, N. C.; MIZIARA, F.; RIBEIRO, N. V. Preço da terra em Goiás: pressupostos e modelos. Boletim Goiano de Geografia, Goiânia, v. 7, n. 1, ed. Especial, p. 47-62, 2007.

FRANÇA, M. de S. As exportações do sul de Goiás no decênio de 1920. Boletim Goiano de Geografia, 1981. Disponível em: www.revistas.ufg.br/index.php/bgg/article/.../4270. Acesso em: 09 out. 2018.

HOBSBAWM, E. Era dos extremos: o breve século XX 1914-1991. São Paulo: Companhia das Letras, 1995.

JAPIASSU, H. A questão da interdisciplinaridade. In: SEMINÁRIO INTERNACIONAL SOBRE REESTRUTURAÇÃO CURRICULAR, 1994, Porto Alegre, Palestra, Secretaria Municipal de Educação de Porto Alegre, julho de 1994, p. 1-5. Disponível em: http://smeduquedecaxias.rj.gov.br/nead/Biblioteca/Forma\%C3\%A7\%C3\%A3o\%20Continuada/Arti gos\%20Diversos/interdisciplinaridade-japiassu.pdf. Acesso em: 11 jun. 2018.

MARTINS, J. de S. Capitalismo e Tradicionalismo. São Paulo: Pioneira, 1975.

MARTINS, J. de S. Fronteira: a degradação do outro nos confins do humano. São Paulo: Contexto, 2018.

MARTINS, J. de S. Reforma Agrária: o impossível diálogo. São Paulo: USP, 2000.

MARX, K. O capital. Crítica da economia política. São Paulo: Abril, 1984.

MIZIARA, F. Condições Estruturais e Opção Individual na Formulação do Conceito de "Fronteira Agrícola”. In: SILVA, L. S. (Org.). Relações Cidade-Campo: Fronteiras. Goiânia: Cegraf, 2000. p. 273-289.

MORAES, A. C. R.; COSTA, W. M. Geografia crítica: a valorização do espaço. São Paulo: Hucitec, 1987.

OLIVEIRA, A. S. et al. O estado de Goiás no contexto nacional. In: CASTRO, J. D. B. et al. (Org.). Economia e responsabilidade socioambiental em Goiás. Anápolis: Universidade Estadual de Goiás, 2011. Cap. 1. p. 13-43.

OLIVEIRA, F. de. Elegia para uma re(li)gião: Sudene, Nordeste. Planejamento e conflito de classes. Rio de Janeiro: Paz e Terra, 1980.

OLIVEIRA, H. A. de. Ocupação, povoamento e início do desenvolvimento dos meios de transportes no sul de Goiás. In. SILVA, L.; OLIVEIRA, E.; MELLO, M. de. (Orgs.). Território, cidades e cultura no Cerrado. Anápolis: UEG, 2012.

OLIVEIRA, H. A. de. Os desafios da viabilidade financeira das companhias de estradas de ferro Mogyanna e Goyaz em suas incursões ao Planalto Central do Brasil. In. REIS, F.; MACÊDO, M. (Orgs.). Desenvolvimento socioeconômico e sustentabilidade do Cerrado brasileiro na transposição do século XX para o XXI. Jundiaí: Paco Editorial, 2016.

REZENDE, G. Ocupação agrícola e estrutura agrária no cerrado: o papel do preço da terra, dos recursos naturais e da tecnologia. Rio de Janeiro: IPEA, 2002. 
RICARDO, D. Princípios de economia política e tributação. São Paulo: Nova Cultural, 1996.

ROCHA, G. F. et al. Detecção de desmatamentos no Bioma Cerrado entre 2022 e 2009: padrões, tendências e impactos. Revista Brasileira de Cartografia, Uberlândia, v. 3, n. 63, p. 340-349, 2011. Disponível em: http://www.lsie.unb.br/rbc/index.php/rbc/index. Acesso em: 04 set. 2018.

RODRIGUES, L. S. Formação do preço da terra rural em Goiás. 2005. Dissertação. Mestrado em Agronegócio, Faculdade de Agronomia, Universidade Federal de Goiás, Goiânia.

SANO, E. E. et al. Mapeamento semidetalhado do uso da terra do bioma Cerrado. Pesquisa Agropecuária Brasileira, Brasília, v. 43, n. 1, p. 153-156, 2008. Disponível em: http://www.scielo.br/scielo.php?script=sci_arttext\&pid=S0100-204X2008000100020. Acesso em: 04 set. 2018.

SANTOS, M. Urbanização brasileira. São Paulo: EdUsp, 2013.

SIEG-MAPAS. Disponível em: http://www.sieg.go.gov.br/siegmapas/mapa.php. Acesso em: 09 jul. 2020.

SILVA, S. D. e; MOURA, T. T. R. L. de; CAMPOS, F. I. A fronteira do gado e a história do oeste brasileiro: coronelismo, violência e dominação fundiária em Goiás. In: FRANCO, José Luiz de Andrade et al. (Org.). História Ambiental: territórios, fronteiras e biodiversidade. Rio de Janeiro: Garamond, 2016. p. 259-286.

SMITH, R. Propriedade da Terra \& Transição: estudo da formação da propriedade privada da terra e transição para o capitalismo no Brasil. São Paulo: Brasiliense, 1990.

STEINBERGER, M. O significado da região CO na espacialidade do desenvolvimento brasileiro: uma análise geopolítica. In: GONÇALVEZ, M. F.; BRANDÃO, C. A.; GALVÃO, A. C. Regiões e cidades, cidades nas regiões, o desafio urbano-regional. São Paulo: Unesp, 2000. p. 31-49.

\section{Fontes documentais consultadas}

A Informação Goyana, v.12, n. 7, ano 13, p. 1345, fev. 1929.

Álbum Brasileiro - Progresso maravilhoso do torrão goiano. Publicação avulsa editado por João de Minas no ano de 1927.

Recenseamento Geral do Brasil: aspecto physico do Brazil - Geologia, flora e fauna - Evolução do povo brazileiro - Histórico dos inquéritos demográficos. Disponível em: https://biblioteca.ibge.gov.br/visualizacao/livros/liv6446.pdf. Acesso em: 09 out. 2018.

Artigo recebido em 02/03/2020. Aceito para publicação em 23/07/2020. 